\title{
BIRDS
}

\section{GREAT HORNED OWL NESTING ON A CLIFF AND GAS PLANT TOWER IN ALBERTA}

MICHAEL I. PRESTON and GRAHAME M. BOOTH, Apt. $201361549^{\text {th }}$ Street N.W.,Calgary, AB T3A 2LT

\section{Introduction}

The Great Horned Owl (Bubo virginianus) has the most extensive range and the most variable nesting sites of any North American owl. ${ }^{4}$ In Alberta, it is widely dispersed, nesting most commonly in parkland regions (46\% of surveyed $10 \mathrm{~km}^{2}$ squares) and least commonly in the Rocky Mountains (13\% of surveyed squares). ${ }^{9}$

Nest site selection may depend on environmental variations in site availability, relative prey distribution, and in some cases, relative freedom from human disturbance. ${ }^{5}$ Throughout North America, the most commonly used nest sites are tree nests of other species, but cavities in trees and snags, cliffs, deserted buildings, and artificial platforms are also used. ${ }^{4}$ Known nest sites in Alberta include primarily abandoned hawk or crow nests and occasionally hollow trees that have been found in forests, woodlots, groves, coulees, and river valleys. ${ }^{7,9}$ This paper documents possibly the first occurrence in Alberta of a Great Horned Owl nesting on a cliff ledge (M. Preston) and among a human-made structure (G. Booth).

\section{Cliff Site}

Johnston Canyon, in Banff National Park, is relatively narrow and formed primarily of steep and jagged limestone that has been gradually eroded by

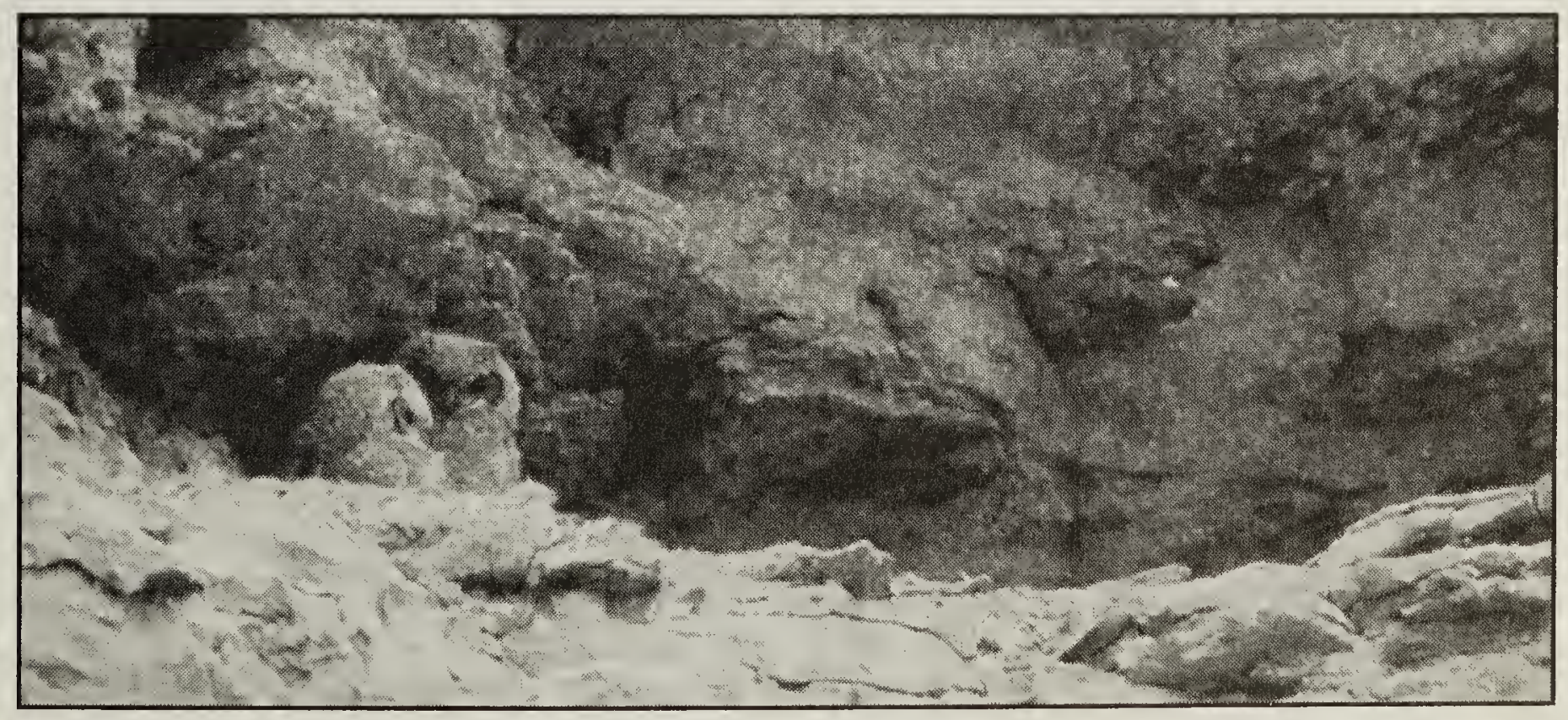

Figure 1 - Two Great Horned owlets on a cliff ledge at Johnston Canyon, Banff National Park, 31 May 1998. Michael Preston 
Johnston Creek. The canyon seldom exceeds $15 \mathrm{~m}$ across, except in areas where the upper and lower falls pour into their respective basins. The surrounding habitat of the canyon is primarily coniferous, with white spruce (Picea glauca) dominating. The deeply shaded and often damp canyon also supports many mosses and low-growing plants. The characteristic mammals include Least Chipmunk (Tamias minimus), Red Squirrel (Tamiasciurus hudsonicus) and Columbian Ground Squirrel (Spermophilus columbianus), with the latter occurring mainly at the base of the canyon where tourists park their vehicles.

This nest was located about $500 \mathrm{~m}$ from the parking area, up Johnston Creek, and opposite the footpath. At about $10 \mathrm{~m}$ above the surface of the creek, a fairly shallow but wide crevice supported the nest. On 31 May 1998, two flightless young were observed on the lip of the ledge (Fig 1). Adult birds were not observed and no prey remains were found. The depth of the ledge could not be determined, nor was it clear whether the nest was a simple scrape without nesting material from a previous occupant.

The use of cliff sites by Great Horned Owls is probably more common in Alberta than is known. However, access to such potential sites by humans is probably limited, as Great Horned Owls nest early in the season when many regions are snowed in. In the eastern Great Basin Desert, Utah, cliff faces and rock outcrops were favored sites, ${ }^{10}$ while in the intermountain West, nest holes in cliffs were used for many years. ${ }^{4}$ In British Columbia, $20 \%$ of natural sites were among cliffs, ${ }^{1}$ further suggesting that this behavior is not all that uncommon.

\section{Gas Plant Site}

During the breeding season of 1997 , the Rockyview Wildlife Recovery Center learned of a grounded owlet at the Amoco Canada Petroleum

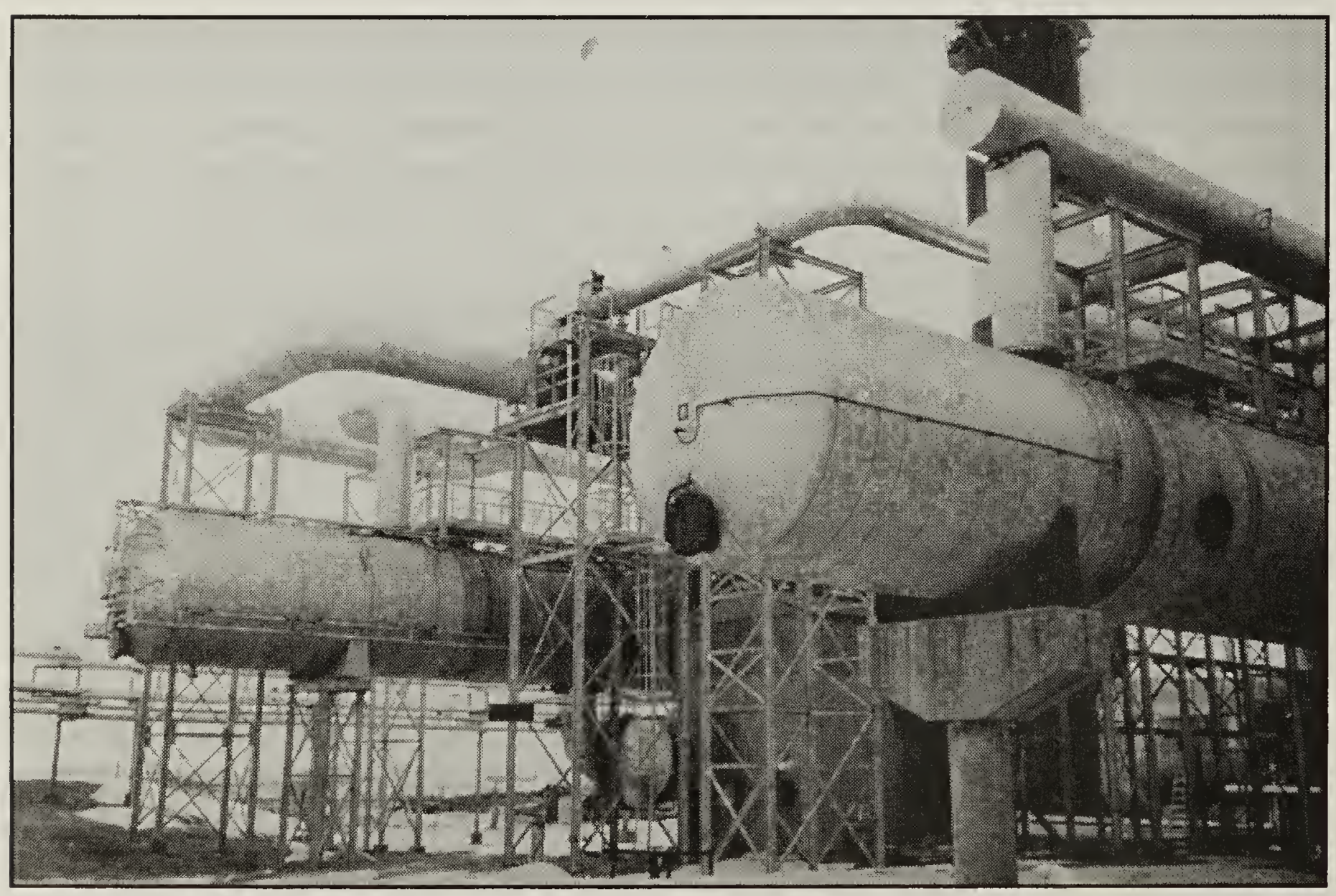

Figure 2. - Great Horned OwI nest location at gas plant, Crossfield, Alberta Gordon Clayholt 
Company Ltd. gas plant, just south of Crossfield, AB., approximately $45 \mathrm{~km}$ north of Calgary, $A B$. Unfortunately, neither the owlet or adults could be found during a visit on 15 May 1997 a few days after the initial report. The plant shift crew also commented that the owls had nested successfully at the plant in 1996. In the 1998 breeding season, two young of normal age were banded during a visit on 5 May. The nest is vacant in 1999.

The nest location is near the top of a metal pipe rack tower, approximately $12 \mathrm{~m}$ above the ground (Fig. 2). The actual nest site is located in a "hot box" near the top of the tower, below the smaller pipe coming in from the right and just above the larger pipe situated above the left horizontal tank. Inside the box is a network of utility and process piping wrapped with a considerable amount of insulation. This probably provided additional warmth to the nest area and possibly influenced the selection of this site. To the left side of the various valves and pipes is the nest, already vacated by the young. The nest sits on the middle of three valves near the middle of the upright hot box (Fig. 3). Our best guess is that the nest was built by Rock Doves (Columba livia) in 1995 or earlier. Additional nest materials were minimal and included small twigs and dried grasses. Large quantities of pellets were present.

Great Horned Owls occasionally use human-made structures. These include nest baskets, ${ }^{8}$ nest tires on poles or trees, ${ }^{6}$ metal bridges, ${ }^{1}$ platforms, ${ }^{2,4}$ and various buildings that include barns, granaries, sheds and houses. ${ }^{3}$ In Saskatchewan, 53 of 2,923 nests $(1.8 \%)$ were in human-made structures, ${ }^{4}$ while near Cincinnati, Ohio, 54 of 738 nests $(7.3 \%)$ were human-made. $^{2}$

\section{Conclusion}

The use of unusual nest sites can be a consideration when managing habitat for wildlife. Wildlife must continually try to adapt to the changes humans make to the environment. Several species use human-made structures, some of which are specifically designed as management tools, while others are used naturally. Although the Great Horned Owl occasionally attacks people approaching a nest, it never deserts its nest because of such visits. Use of the Johnston Canyon and Amoco nest sites appears to have caused little stress to the owls, and provides further evidence of the adaptability of the Great Horned Owl.

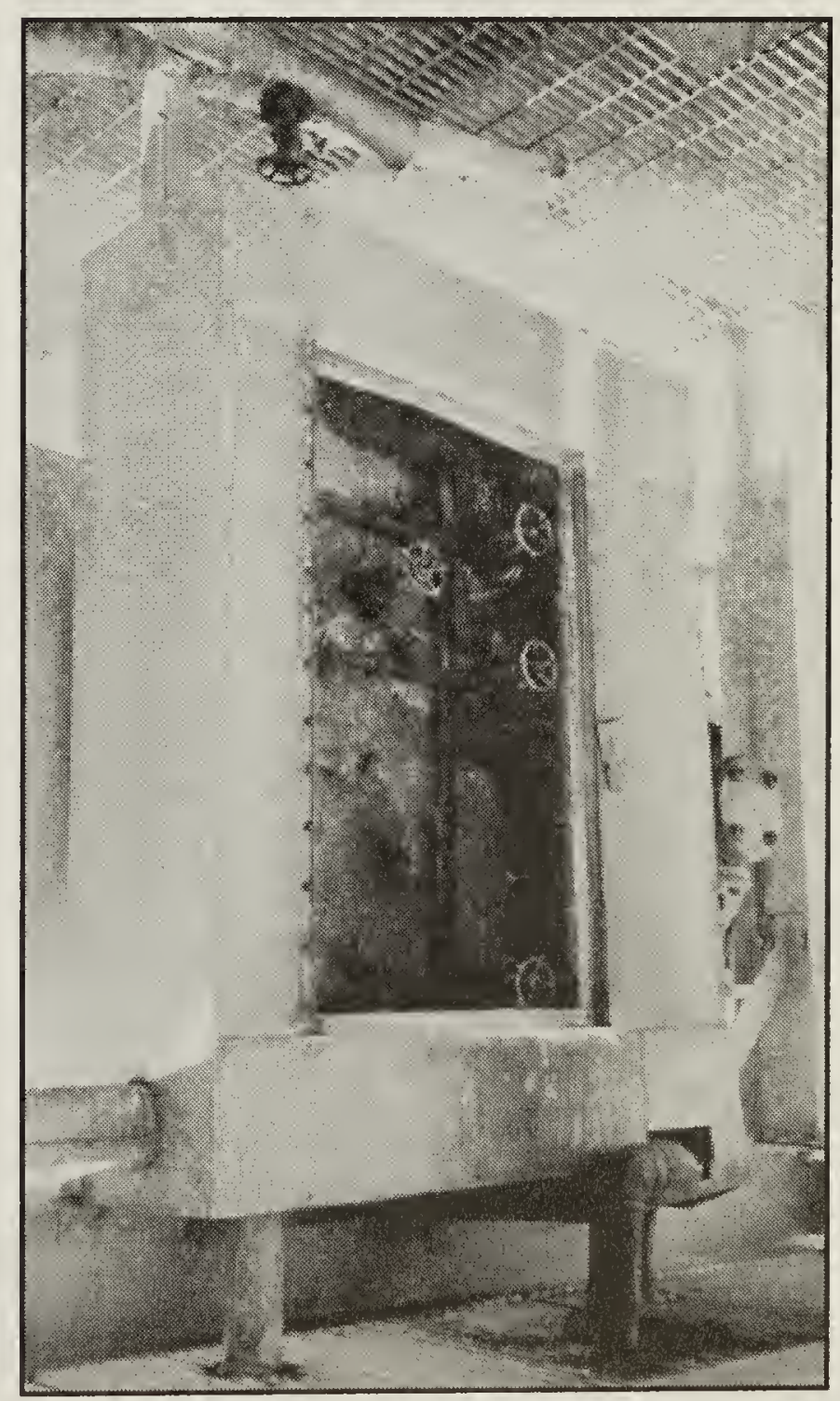

Figure 3. Electrical hot box containing a Great Horned Owl nest, used successfully, 1996-1998.

Gordon Clayholt, taken after owls fledged 


\section{Acknowledgements}

The authors graciously thank R.W. Campbell, C.S. Houston, and J.K. Schmutz for critically reviewing this manuscript and offering suggestions for improvement. We also thank G. Clayholt and other employees of Amoco Canada for their assistance. Thanks to D. Rowell of the Rockyview Wildlife Recovery center for informing us of the gas plant nest site. Our thanks also to C.S. Houston and E. Pletz for contributing helpful information on working with Great Horned Owls at the nest.

1. CAMPBELL, R.W., N.K. DAWE, I. MCTAGGART-COWAN, J.M. COOPER, G.W. KAISER, M.C.E. MCNALL. 1990. The birds of British Columbia, volume two - nonpasserines: diurnal birds of prey through woodpeckers. Royal British Columbia Museum, Victoria. 636pp.

2. HOLT, J.B., Jr. 1996. A banding study of Cincinnati area Great Horned Owls. J. Raptor Res. 30: 194-197.

3. HOUSTON, C.S. 1996. Great Horned Owl nest sites in Saskatchewan. Blue Jay 54: 125-133.

4. HOUSTON, C.S., D.G. SMITH, AND C.ROHNER. 1998. Great Horned Owl (Bubo virginianus). In The birds of North America, No.372 (A. Poole and F. Gill, eds.). The birds of North America, Inc., Philadelphia, PA.
5. JOHNSGARD, P.A. 1988. North American owls: biology and natural history. Smithsonian Institution Press, Washington.

6. MILLSAP, B.A., K.W. CLINE, AND B.A.G. PENDLETON. 1987. Habitat management. Pp. 215-237 in Raptor Management Techniques Manual (B.A.G. Pendleton, B.A. Millsap, K.W. Cline and D.M. Bird, eds.). Nat. Wildl. Fed. Sci. Tech. Ser. No. 10: 1-4.

7. SALT, W.R. AND J.R. SALT. 1976. The birds of Alberta. Hurtig Publishers, Edmonton, Alberta.

8. SCOTT, L. 1970. Great Horned Owls occupy artificial nesting site. Blue Jay 28:123.

9. SEMENCHUK, G. 1992. The atlas of breeding birds of Alberta. Federation of Alberta Naturalists, Edmonton, Alberta. $391 \mathrm{pp}$.

10. SMITH, D.G., AND J.R. MURPHY. 1973. Breeding ecology of raptors in the eastern Great Basin Desert of Utah. Raptor Research 13: 1-14.

One swallow does not a summer make, but one skein of geese, cleaving the murk of a March thaw, is the spring. Aldo Leopold. 